\title{
Consórcio de milho com forrageiras: atributos físicos do solo e produtividade de
} massa seca

\author{
Leonardo Santiani ${ }^{1}$, Otavio Bagiotto Rossato ${ }^{2}$, Renata Pizzatto Contini ${ }^{2}$, Igor Vortmann ${ }^{2}$, Jeizon Eisenhardt ${ }^{2}$ \\ ${ }^{1}$ Universidade do Estado de Santa Catarina - UDESC. ${ }^{2}$ Instituto Federal Catarinense - IFC, Concórdia, SC. E-mail: \\ santiani-Is@hotmail.com
}

\section{Resumo}

Objetivou-se com esse trabalho avaliar a produtividade de massa seca de milho no consórcio com forrageiras ou em cultivo solteiro, aveia+azevém em sucessão e os atributos físicos em um Nitossolo Vermelho. O experimento foi conduzido em Concórdia - SC nos anos agrícolas de 2016/2017 e 2017/2018. $O$ delineamento foi de blocos ao acaso com 5 repetições, composto pelos tratamentos: T1 - Milho solteiro; T2 - Milho + F. Guandu (Cajanus cajan); T3 - Milho + U. ruziziensis; T4 - Milho + F. Guandu + U. ruziziensis, T5 - F. Guandu solteiro e T6 - U. ruziziensis solteira. Foi determinada a produtividade de massa seca (PMS) do milho, das forrageiras e da aveia+azevém em sucessão. Realizou-se também o Diagnóstico Rápido de Estrutura do Solo (DRES) e a Resistência mecânica do Solo a Penetração (RSP) após dois anos de cultivo. A presença da $U$. ruziziensis e/ou do F. Guandu não interferiram na produtividade de massa seca do milho em ambas as safras. As maiores PMS da aveia foram encontradas nas parcelas em sequência ao milho solteiro e, as menores para a segunda safra onde sucedeu-se à tratamentos com presença de $U$. ruziziensis. Para RSP não foram obtidas diferenças significativas nos consórcios e nos cultivos solteiros. Os tratamentos com $U$. ruziziensis obtiveram melhores índices de qualidade estrutural. O consórcio milho com Urochloa ruziziensis além de não reduzir a produtividade da silagem, propicia disponibilidade de forragem no período de vazio outonal, bem como melhoria nos atributos do solo.

Palavras-chave: Cajanus cajan; integração lavoura pecuária; Urochloa ruziziensis; Zea mays.

\section{Corn consortium with forages: soil physical attributes and yield dry mass}

\begin{abstract}
The objective of this work was to evaluate the productivity of maize dry matter in the consortium with forage or in single cultivation, oats + ryegrass in succession and the physical attributes in a Red Nitosol. The experiment was conducted in Concórdia - SC in the agricultural years 2016/2017 and 2017/2018. The design was a randomized block with 5 replications, consisting of the treatments: T1 - Single maize; T2 Maize + Pigeon pea forage (Cajanus cajan); T3 - Maize + Urochloa ruziziensis; T4 - Maize + Pigeon pea forage $+U$. ruziziensis, T5 - Pigeon pea forage and T6 - U. ruziziensis single. The dry mass productivity (PMS) of maize, forage and oats + ryegrass in succession was determined. Also, the Rapid Diagnosis of Soil Structure (DRES) and the Mechanical Resistance of Soil to Penetration (RSP) were carried out after two years of cultivation. The presence of $U$. ruziziensis and / or Pigeon pea did not affect the dry matter yield of maize in both harvests. The highest PMS of oats were found in the plots following single maize and the smallest for the second crop, where treatments with U. ruziziensis followed. For RSP, no significant differences were found in consortia and single crops. The treatments with $U$. ruziziensis obtained better indexes of structural quality. The corn consortium with Urochloa ruziziensis, in addition to not reducing silage productivity, provides forage availability in the autumn empty period, as well as improving soil attributes.
\end{abstract}

Keywords: Cajanus cajan; crop-livestock integration; Urochloa ruziziensis; Zea mays. 


\section{Introdução}

Nas últimas décadas, as áreas agrícolas utilizadas em sistema de integração lavourapecuária (ILP) vem se tornando mais expressivas no Brasil, em virtude dos inúmeros benefícios que podem ser obtidos (MACEDO, 2009). Esse sistema se caracteriza pela sucessão entre a produção de grãos e pastejo de animais em uma mesma área, em que permite-se a diversificação da produção, indução de rotação de culturas e ciclagem de nutrientes (KUNZ et al., 2013), além de aumentar a matéria orgânica melhorando a estrutura física do solo, principalmente seu espaço poroso (FLORES et al., 2007).

O Oeste Catarinense é caracterizado pela alta participação na cadeia da bovinocultura leiteira, representando $79 \%$ da produção do estado, onde esta atividade se concentra em pequenas propriedades com agricultura familiar e alta diversificação das atividades agropecuárias (CEPA, 2018). O relevo da região apresenta elevada declividade, limitando os tratos culturais e em conjunto com os períodos de transição como o "vazio forrageiro outonal", tornam necessária a produção de ensilados para suprir a demanda da nutrição animal (SCHEFFER-BASSO et al., 2004).

A produção de ensilados gera um elevado tráfego de máquinas e se concentra em meses com alta precipitação e reduzida janela de trabalho, ocasionada pela frequência de dias chuvosos (EMBRAPA, 2017). O tráfego nos períodos após as chuvas em que a umidade do solo está próxima ao limite de plasticidade, influencia na compactação, uma vez que a água reduz a coesão e atua como lubrificante entre as partículas de solo, ocorrendo o deslizamento e o empacotamento quando este é submetido a pressão (LUCIANO et al., 2012).

A compactação é agravada no decorrer da estação fria, já que as áreas são utilizadas para pastejo. $O$ superpastejo que ocorre em alguns locais e remove toda biomassa que protege 0 solo, juntamente com o pisoteio animal, podem ter efeito adverso sobre as propriedades físicas por alterar o sistema poroso, refletindo no movimento de água e ar na camada superficial do solo (KUNZ et al., 2013). Esses fatores podem gerar limitações ao crescimento das plantas, principalmente quando o pisoteio ocorre com teor de água favorável à compactação (COLLARES et al., 2011).
A utilização de plantas que possuam sistema radicular volumoso e agressivo tem se mostrado eficientes e com maior potencial para estruturar solos compactados a longo prazo (CALONEGO et al., 2011b). O Feijão Guandu (Cajanus cajan) possui um sistema radicular profundo, que além de reciclar nutrientes, possibilita romper camadas compactadas e adensadas do solo, auxiliando na diminuição da resistência a penetração (FARIAS et al., 2013). A Urochloa ruziziensis é uma das gramíneas com maior potencial para promover melhorias à estrutura do solo em razão da quantidade, qualidade e distribuição de fitomassa radicular (CALONEGO et al., 2011a). Embora as avaliações da qualidade do solo sejam baseadas principalmente em abordagens analíticas, as avaliações visuais a campo ajudam os agricultores, consultores e pesquisadores a analisar os solos de maneira rápida e barata (VALANI et al. 2020). O Diagnóstico Rápido da Estrutura do Solo (DRES) consiste em um teste para avaliar a estrutura do solo em relação às características visuais (RALISCH et al., 2017). O DRES é uma alternativa viável e rápida de avaliação estrutural do solo, com intervenção mínima no local e grande sensibilidade para detectar diferenças de manejo do solo (RALISCH et al., 2017; VALANI et al., 2020).

Portanto, dada a carência de informações científicas sobre estas questões em Santa Catarina, objetivou-se com este trabalho avaliar a produtividade de massa seca de milho em consórcio com forrageiras ou em cultivo solteiro, do consórcio de aveia+azevém em sucessão e os atributos físicos em um Nitossolo Vermelho em Concórdia - SC.

\section{Material e métodos}

O experimento foi conduzido nos anos agrícolas de 2016/2017 e 2017/2018, na Fazenda experimental do Instituto Federal Catarinense IFC, Campus Concórdia, localizada no município de Concórdia, SC $\left(27^{\circ} 12^{\prime} 25.2^{\prime \prime}\right.$ S e $\left.52^{\circ} 05^{\prime} 14.5^{\prime \prime} \mathrm{W}\right)$. A altitude é de $596 \mathrm{~m}$ e o clima, de acordo com a classificação de Köppen, é predominantemente subtropical úmido ( $\mathrm{Cfa}$ ), com temperatura média anual de $19,6{ }^{\circ} \mathrm{C}$ e precipitação pluvial anual de 1.700 a $2.200 \mathrm{~mm}$ (EMBRAPA, 2017). O solo da área experimental é classificado como Nitossolo Vermelho (SANTOS et al., 2018) de textura argilosa $\left(0,45 \mathrm{~kg} \mathrm{~kg}^{-1}\right.$ de argila, $0,41 \mathrm{~kg} \mathrm{~kg}^{-1}$ de silte e $0,14 \mathrm{~kg} \mathrm{~kg}^{-1}$ de areia, na camada de $0-20 \mathrm{~cm}$ ). 
Os atributos químicos e físicos anteriormente à instalação do experimento indicaram: $\mathrm{pH}\left(\mathrm{H}_{2} \mathrm{O}\right)$ de 5,7, pH SMP de 6,1, $\mathrm{H}+\mathrm{Al}$ de $3,9 \mathrm{cmol}_{\mathrm{c}} \mathrm{dm}^{-3}$; $\mathrm{Al}$ de $0,0 \mathrm{cmol}_{\mathrm{c}} \mathrm{dm}^{-3}$, matéria orgânica de 3,9\%, teores de $\mathrm{P}$ e $\mathrm{K}$ disponíveis de 63 e $250 \mathrm{mg} \mathrm{dm}^{-3}$, respectivamente, conforme Tedesco et al. (1995).

A área experimental possuía como histórico o cultivo de milho para produção de silagem no verão e aveia preta (Avena strigosa Schreb) e azevém (Lolium multiflorum) no inverno. Na Figura 1, estão apresentados os dados de precipitação pluvial e temperatura média no período experimental. $O$ delineamento utilizado foi o de blocos ao acaso com cinco repetições, composto pelos tratamentos: T1 Milho solteiro (M); T2 - Milho + F. Guandu forrageiro (MG); T3 - Milho + U. ruziziensis (MB); T4 - Milho + F. Guandu forrageiro + U. ruziziensis (MBG), T5 - F. Guandu forrageiro solteiro (G) e T6 - U. ruziziensis solteira (B). Cada unidade experimental foi composta por $10 \mathrm{~m}$ de comprimento e $4,8 \mathrm{~m}$ de largura, totalizando uma área de $48 \mathrm{~m}^{2}$, constituída por 6 linhas de milho espaçadas em $0,8 \mathrm{~m}$. A área útil da parcela foi de $20 \mathrm{~m}^{2}$, representando as 4 linhas centrais e desconsiderando as linhas de borda.

Figura 1. Dados de precipitação acumulada $\left(\mathrm{mm}\right.$ mês $\left.\mathrm{s}^{-1}\right)$ e temperatura média mensal $\left({ }^{\circ} \mathrm{C}\right)$ ocorridas durante os meses de dezembro de 2016 a novembro de 2018, correspondente ao período das safras de 2016/2017 e 2017/2018 obtidos na estação meteorológica da Embrapa Suínos e Aves, em Concórdia, SC.

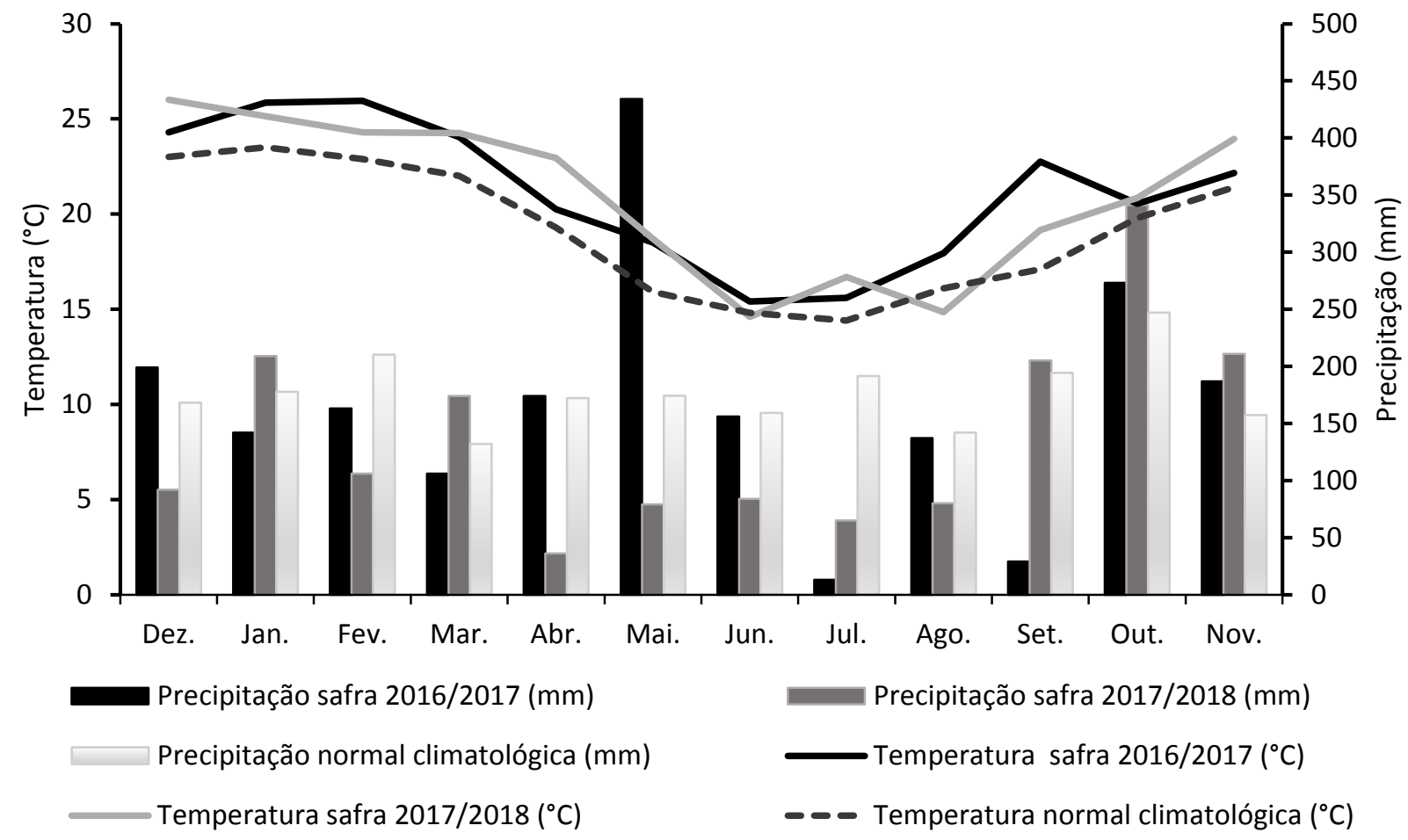

A área foi dessecada 30 dias antes da semeadura do milho na safra de 2016/2017, utilizando os herbicidas Glifosato e Paraquate. Os cultivos solteiros e o consórcio com linhas alternadas de milho $+U$. ruziziensis e/ou $\mathrm{F}$. Guandu foi implantado em 07/12/2016, utilizando semeadora-adubadora de grãos graúdos modelo SAM 500 -Semeato, ajustando-a para semeadura de uma linha de milho e outra de F. Guandu. As linhas de milho e as de F. Guandu ficaram espaçadas $0,80 \mathrm{~m}$ entre si. Nos tratamentos com a presença de $U$. ruziziensis, as sementes foram semeadas junto com os fertilizantes, com a mistura no momento da semeadura. Determinou-se a densidade de semeadura de acordo com o valor cultural (V.C), utilizando $10 \mathrm{~kg} \mathrm{ha}^{-1}$ para a U. ruziziensis (V.C. $85 \%), 40 \mathrm{~kg} \mathrm{ha}^{-1}$ de F. Guandu, cultivar BRS Mandarim e 65.000 sementes $\mathrm{ha}^{-1}$ de milho híbrido VT PRO 2 Limagrain. Na adubação de semeadura foram aplicados $31,5 \mathrm{Kg}^{-1}$ de $\mathrm{N} ; 115,5$ $\mathrm{kg}^{-1}$ de $\mathrm{P}_{2} \mathrm{O}_{5}$ e $42 \mathrm{~kg}^{-1}$ de $\mathrm{K}_{2} \mathrm{O}\left(350 \mathrm{~kg} \mathrm{ha}^{-1}\right.$ do formulado 9-33-12) e, $150 \mathrm{~kg} \mathrm{ha}^{-1}$ de $\mathrm{N}$ em cobertura no estádio fenológico do milho V6, adubação baseada nas recomendações de 
adubação para os estados do RS e SC (CQFS$\mathrm{RS} / \mathrm{SC}, 2016$ ).

A colheita manual do milho foi realizada em 05/04/2017, aos 119 dias após semeadura (DAS), coletando-se 3 metros lineares por parcela para estimativa da produtividade de massa seca no estádio recomendado para colheita para silagem que corresponde a $30-35 \%$ de massa seca (ZHANG et al., 2015). Avaliou-se a produtividade de massa seca (PMS) das forrageiras, com a coleta de 4 amostras de $3 \mathrm{~m}^{2}$ $(3,0 \times 1,0 \mathrm{~m})$ dentro de cada unidade experimental. Em cada amostragem o material cortado foi pesado e as amostras colocadas em estufa de ventilação forçada de ar a $65^{\circ} \mathrm{C}$ até atingir massa constante, para a quantificação da PMS (kg ha $\left.{ }^{-1}\right)$. Após a colheita manual, foi realizada a colheita de forma mecanizada com ensiladeira, a fim de impor na área os impactos do tráfego de máquinas ao solo, utilizando um trator Valtra 885TS acoplado com ensiladeira Nogueira Pecus 9004 e carreta basculante Ipacol trucada 6 toneladas.

Para a instalação e a condução do experimento na safra de 2017/2018, foram adotados os mesmos procedimentos descritos anteriormente para a safra de 2016/2017. Para tanto, a semeadura do milho e das espécies forrageiras foi realizada em 23/11/2017 e a colheita do milho ocorreu em 21/03/2018, o que correspondeu também a 118 DAS.

$\mathrm{Na}$ estação fria realizou-se sobressemeadura com pastagem anual de aveia preta com $70 \mathrm{~kg} \mathrm{ha}^{-1}$ de sementes em 08/05/2017 e 09/05/2018, respectivamente para $\circ 1^{\circ}$ e $2^{\circ}$ anos agrícolas. $\mathrm{Na}$ área ocorreu também a ressemeadura natural do banco de sementes do solo de azevém. Foram realizadas duas coletas, sendo na 1a safra aos 61 e 115 dias após semeadura (DAS) e na 2a aos 86 e 151 DAS, com a aplicação de $80 \mathrm{~kg} \mathrm{ha}^{-1}$ de $\mathrm{N}$ após o primeiro corte em ambas as safras. Para a coleta foi realizada a marcação com estacas, e o corte a $0,10 \mathrm{~m}$ de altura, coletando 3 amostras aleatórias de 0,25 $\mathrm{m}^{2}$ de aveia/azevém por parcela e após foram secas em estufa a $65^{\circ} \mathrm{C}$ até atingir peso constante para determinação da PMS ( $\left.\mathrm{kg} h \mathrm{~h}^{-1}\right) . \mathrm{Na}$ sequência de cada corte foi realizado o pastejo com vacas da raça holandesa, em média por dois dias.

Após os dois anos de condução do experimento, avaliou-se em cada parcela a Resistência mecânica do Solo à Penetração (RSP) e o Índice de Qualidade Estrutural do Solo (IQES). A RSP foi determinada com o penetrômetro de impacto (modelo IAA/Planalsucar-Stolf) e os resultados transformados segundo Stolf (1991). Para avaliação da RSP foram realizados 3 pontos de avaliação por parcela até a profundidade de 0,60 m., onde cada ponto foi composto por 4 locais de avaliação, sendo um sobre a linha do milho nos consórcios e no milho solteiro, ou sobre a linha das forrageiras na ausência do milho, mais 3 pontos à direita da linha do milho ou das forrageiras solteiras distanciados $0,10 \mathrm{~m}$ entre si.

Para a avaliação do (IQES) seguiu-se o método do Diagnóstico Rápido da Estrutura do Solo (DRES) descrito por Ralisch et al. (2017). Foram retiradas 4 amostras por parcela, com a coleta ao lado da linha do milho nos consórcios e milho solteiro ou das forrageiras nos cultivos com ausência de milho. Coletou-se uma fatia do solo com as dimensões de $0,20 \mathrm{~m}$ de comprimento $x$ $0,10 \mathrm{~m}$ de largura $\times 0,25 \mathrm{~m}$ de profundidade. Com a espessura e as notas de cada camada (Qec), calculou-se o Índice de Qualidade Estrutural do solo da Amostra (IQEA), por meio da equação:

$$
I Q E A=\frac{(\mathrm{Ec} 1 \cdot \mathrm{Qec} 1)+(\mathrm{Ec} 2 \cdot \mathrm{Qec} 2)}{\text { Etotal }}
$$

Sendo Ec: espessura de cada camada $(\mathrm{cm})$; Qec: notas de cada camada; Etotal: Profundidade total da amostra. A média das amostras forma o índice de qualidade estrutural do solo (IQES). Os dados foram submetidos à análise de variância e as médias comparadas pelo Teste LSD de Fisher $(\mathrm{P}<0,05)$, com o programa SISVAR ${ }^{\circ}$ (FERREIRA, 2011).

\section{Resultados e discussão}

A análise de variância revela que no consórcio de milho com forrageiras nas safras 2016/2017 e 2017/2018, a PMS do milho não apresentou diferenças significativas, com P-valor maior que 0,05 (Tabela 1), o mesmo ocorreu para a RSP, onde o penetrômetro não identificou diferenças entre os tratamentos para todas as profundidades avaliadas. 
Tabela 1. Resumo da análise de variância (ANOVA) da produtividade de massa seca (PMS) do milho, F. Guandu, U. ruziziensis, PMS total e do consórcio aveia+azevém e, dos atributos do solo pela Resistência mecânica do Solo a Penetração e Diagnóstico Rápido de Estrutura do Solo (DRES), Concórdia, SC.

\begin{tabular}{|c|c|c|c|c|c|c|}
\hline \multirow{2}{*}{ Fatores } & \multicolumn{6}{|c|}{ Consórcio milho e forrageiras $2016 / 17$} \\
\hline & Milho & & U. ruziziensis & F. Guandu & & Total \\
\hline P valor & $0,77 \mathrm{~ns}$ & & $0,00 *$ & $0,00 *$ & & $0,002^{*}$ \\
\hline CV (\%) & 11 & & 11,3 & 17,2 & & 10,5 \\
\hline \multirow{2}{*}{ Fatores } & \multicolumn{6}{|c|}{ Consórcio milho e forrageiras $2017 / 18$} \\
\hline & Milho & & U.ruziziensis & F. Guandu & & Total \\
\hline P valor & $0,69 \mathrm{~ns}$ & & $0,00^{*}$ & $0,00 *$ & & $0,00^{*}$ \\
\hline CV (\%) & 3,35 & & 6,38 & 10,5 & & 7,84 \\
\hline \multirow{2}{*}{ Fatores } & \multicolumn{3}{|c|}{ Aveia+Azevém } & \multicolumn{3}{|c|}{ DRES } \\
\hline & Safra 2017 & & Safra 2018 & \multicolumn{3}{|c|}{ IQES } \\
\hline P valor & $0,000^{*}$ & & $0,008^{*}$ & \multicolumn{3}{|c|}{$0,018^{*}$} \\
\hline CV (\%) & 3,0 & & 7,46 & & 7,82 & \\
\hline \multirow{2}{*}{ Fatores } & \multicolumn{6}{|c|}{ Resistência Mecânica a penetração } \\
\hline & $0,5 \mathrm{~m}$ & $0,15 \mathrm{~m}$ & $0,25 \mathrm{~m}$ & $0,35 \mathrm{~m}$ & $0,45 \mathrm{~m}$ & $0,55 \mathrm{~m}$ \\
\hline P valor & $0,47^{\mathrm{ns}}$ & $0,47^{\mathrm{ns}}$ & $0,91^{\mathrm{ns}}$ & $0,22^{\mathrm{ns}}$ & $0,87^{\mathrm{ns}}$ & $0,59^{\mathrm{ns}}$ \\
\hline CV (\%) & 9,5 & 9,2 & 3,5 & 6,2 & 13,9 & 6,6 \\
\hline
\end{tabular}

*significativo $(\mathrm{P}<0,05)$; ns - Não significativo; CV - Coeficiente de variação.

Para o F. Guandu, U. ruziziensis, total do consórcio, além da aveia+azevém em sucessão a PMS diferiu entre os diferentes tratamentos e arranjos de plantas, o que também foi observado nos Índices de qualidade estrutural avaliados através do DRES.

Na PMS das culturas (Tabela 2) observouse que a presença da $U$. ruziziensis e/ou do $F$. Guandu forrageiro não interferiu na PMS do milho nas duas safras. Para diminuir o efeito de competição no período de desenvolvimento inicial do milho foi utilizada a estratégia de semeadura mais profunda da U. ruziziensis, já o $\mathrm{F}$. Guandu, tem por característica o crescimento mais lento na sua fase inicial (RAYOL; ALVINORAYOL, 2012). Estas respostas estão de acordo com os dados encontrados por Borghi e Crusciol (2007) e Costa et al. (2012). Além disso, outro fator que pode ter contribuído para a baixa interferência das forrageiras cultivadas em consórcio na PMS do milho é a boa disponibilidade hídrica ocorrida durante o ciclo de cultivo em ambos os anos (Figura 1). 
Tabela 2. Produtividade de massa seca $\left(\mathrm{kg} \mathrm{ha}^{-1}\right)$ de Milho, U. ruziziensis, F. Guandu cultivados em consórcio ou solteiros e aveia+azevém cultivados em sucessão nos anos agrícolas de 2016/2017 e 2017/2018. Concórdia, SC.

\begin{tabular}{|c|c|c|c|c|c|}
\hline \multirow[t]{2}{*}{ Tratamentos } & Milho & $\begin{array}{c}U . \\
\text { ruziziensis }\end{array}$ & $\begin{array}{c}\text { F. } \\
\text { Guandu }\end{array}$ & $\begin{array}{c}\text { Total } \\
\text { consórcio }\end{array}$ & Aveia+azevém \\
\hline & \multicolumn{5}{|c|}{$\mathrm{kg} \mathrm{ha}^{-1}$} \\
\hline & \multicolumn{5}{|c|}{ 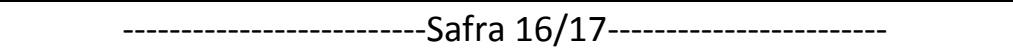 } \\
\hline Milho solteiro & $18.055^{\mathrm{ns}}$ & - & - & $18.055 \mathrm{bc}$ & $8.241 \mathrm{a}$ \\
\hline Milho + F. Guandu & 18.783 & - & $2.288 \mathrm{~b}$ & $21.071 \mathrm{~b}$ & $7.082 b$ \\
\hline Milho + U. ruziziensis & 19.050 & $1.588 \mathrm{~b}$ & - & $20.638 b$ & $6.554 \mathrm{c}$ \\
\hline Milho + U. ruziziensis + F. Guandu & 19.567 & $1.616 \mathrm{~b}$ & $3.570 \mathrm{~b}$ & $24.752 \mathrm{a}$ & $6.413 \mathrm{c}$ \\
\hline Urochloa ruziziensis solteira & - & 17.069 a & - & $17.069 \mathrm{c}$ & $6.639 c$ \\
\hline \multirow[t]{2}{*}{ Feijão Guandu Solteiro } & - & - & $20.460 \mathrm{a}$ & $20.460 \mathrm{~b}$ & $6.613 c$ \\
\hline & \multicolumn{4}{|c|}{ Safra $17 / 18$} & ------ \\
\hline Milho solteiro & $17.115^{\mathrm{ns}}$ & - & - & $17.115 \mathrm{~b}$ & $8.397 \mathrm{a}$ \\
\hline Milho + F. Guandu & 16.664 & - & $1.756 \mathrm{~b}$ & $18.421 \mathrm{ab}$ & $7.945 a b$ \\
\hline Milho + U. ruziziensis & 17.217 & $2.431 \mathrm{~b}$ & - & 19.649 a & $6.773 \mathrm{c}$ \\
\hline Milho + U. ruziziensis + F. Guandu & 16.137 & $1.162 \mathrm{c}$ & $1.316 \mathrm{~b}$ & $18.616 a b$ & $7.476 \mathrm{bc}$ \\
\hline Urochloa ruziziensis solteira & - & $15.234 \mathrm{a}$ & - & $15.234 \mathrm{c}$ & $7.060 \mathrm{c}$ \\
\hline Feijão Guandu Solteiro & - & - & $14.154 \mathrm{a}$ & $14.154 \mathrm{c}$ & $7.990 \mathrm{ab}$ \\
\hline
\end{tabular}

Para os dois anos agrícolas a U. ruziziensis e o F. Guandu quando cultivados solteiros, obtiveram PMS superior se comparado ao seu cultivo em consórcio, explicado pela dificuldade de estabelecimento e o efeito da competição e sombreamento que o milho exerce sobre essas forrageiras. Pariz et al. (2010) também observaram que quando a Urochloa foi implantada em consórcio com o milho, houve competição interespecífica, diminuindo o acúmulo de biomassa da forrageira. 0 sombreamento ocasionado nessas condições faz com que as plantas de Urochloa tornem enfraquecidas, apresentando crescimento lento, principalmente por possuírem metabolismo $\mathrm{C} 4$ de fixação do $\mathrm{CO}_{2}$, tornando-as muito exigentes por luz (PORTES et al., 2000).

A PMS da $U$. ruziziensis nos consórcios não foi afetada pela inserção do F. Guandu na safra 2016/2017, porém, nos consórcios em ambas as safras a produtividade apresentou-se abaixo do potencial produtivo. Para o F. Guandu, apesar da baixa produtividade quando cultivado em consórcio, este foi responsável por cerca de $11 \%$ da massa seca total do consórcio produzida no tratamento $M G$ e cerca de $17 \%$ no $M B G$ na safra 2016/2017 e $9 \%$ e $7 \%$ na safra 2017/2018, respectivamente. Costa et al. (2017a) em consórcio de milho com F. Guandu e capim piatã, encontrou proporções similares, destacando ainda que a adição do F. Guandu incrementa o valor nutricional da silagem e pode reduzir os custos de produção.

Na safra 2016/2017 a PMS total do consórcio aos 119 DAS evidencia que o arranjo das três culturas (MBG) apresenta o maior potencial produtivo por área, sendo superior ao demais arranjos de plantas e os cultivos solteiros. Tais resultados demonstram que é possível o consórcio das três culturas neste sistema de produção visando a produção de silagem, uma vez que a inclusão do F. Guandu além de aumentar a PMS pode ainda melhorar a qualidade nutricional da silagem (COSTA et al., 2015). Entretanto para a safra $2017 / 2018$ a maior PMS total dos consórcios aos 118 DAS demonstra que o tratamento $\mathrm{MB}$ tem produção similar aos demais consórcios e superior aos cultivos solteiros, devido ao melhor desenvolvimento da $U$. ruziziensis nesse tratamento comparado ao MBG, que incrementou a PMS total. O uso do consórcio de culturas é um dos meios para se elevar a produtividade de sistemas de produção integrados (COSTA et al., 2017b; CRUSCIOL et al., 2015), além de demonstrar maior eficiência em preservar os recursos naturais e explorar 
racionalmente os solos (COSTA et al., 2015; PARIZ et al., 2017).

A PMS da aveia + azevém mostra que o consórcio de plantas no cultivo anterior influenciou a produtividade da pastagem de inverno em ambos os anos agrícolas. Para a primeira safra as maiores médias de produtividade se deram exclusivamente no cultivo em sequência ao milho solteiro, tendência que não ocorreu no segundo cultivo. Para ambas as safras as menores PMS foram encontradas nos tratamentos com presença de $U$. ruziziensis anteriormente, onde sua presença e, o maior acúmulo de palhada afetaram a PMS da aveia+azevém. De acordo com Salvador (2007), as plântulas buscam suprir suas necessidades fotossintéticas através da emergência, mas ao se depararem com a palha, que é um impedimento físico, ficam estioladas e fracas, reduzindo sua produtividade.

Deve-se salientar que mesmo obtendo-se menores valores de PMS de aveia+azevém nos consórcios com $U$. ruziziensis, tem-se o benefício da pastagem implantada na entressafra que pode servir como alimento volumoso aos animais após a colheita do material para ensilagem, sendo estratégia para diminuir a lacuna de oferta no vazio forrageiro outonal. Costa et al. (2017b) destacam o uso da combinação de milho com forrageiras tropicais em sistemas consorciados, a fim de proporcionar a formação de pastagem após o processo de ensilagem.

Para RSP, a maior parte das médias encontram-se acima de 2 Mpa (Mega Pascal)
(Figura 2), o que pode causar deformações morfológicas no sistema radicular das culturas (COLLARES et al., 2008). Não foram obtidas diferenças significativas para os consórcios de plantas e cultivos solteiros, indo ao encontro à literatura que indica que as espécies do gênero Urochloa tem satisfatória tolerância à RSP e com isso conseguem reverter situações de compactação (CALONEGO et al., 2011a; CRUSCIOL et al., 2010).

A similaridade entre os tratamentos demonstra a necessidade da condução dos estudos por um maior período de tempo, para que se possa observar mudanças físicas no solo com o penetrômetro, uma vez que são lentamente alteradas e de difícil mensuração. 0 que corrobora com estudos de Torres e Saraiva (1999), afirmando que as diferenças existentes entre os penetrômetros e as raízes, e o surgimento de grande quantidade de bioporos no plantio direto, indicam que nesse sistema não é correto considerar somente as avaliações de penetrômetros para concluir que o solo está compactado. Visto que o penetrômetro é constituído por uma haste metálica com ponta cônica que penetra ao solo (STOLF, 1991), ao contrário das raízes, que crescem em várias direções, não sendo lineares. As características de desenvolvimento das raízes, somadas à heterogeneidade do solo, sugerem que as raízes possuem vantagens mecânicas em relação aos penetrômetros (TORRES; SARAIVA, 1999).

Figura 2. Resistência mecânica do solo à penetração (MPa) em um Nitossolo Vermelho cultivado com milho em consórcio com forrageiras no oeste catarinense. Concórdia, SC, 2018.

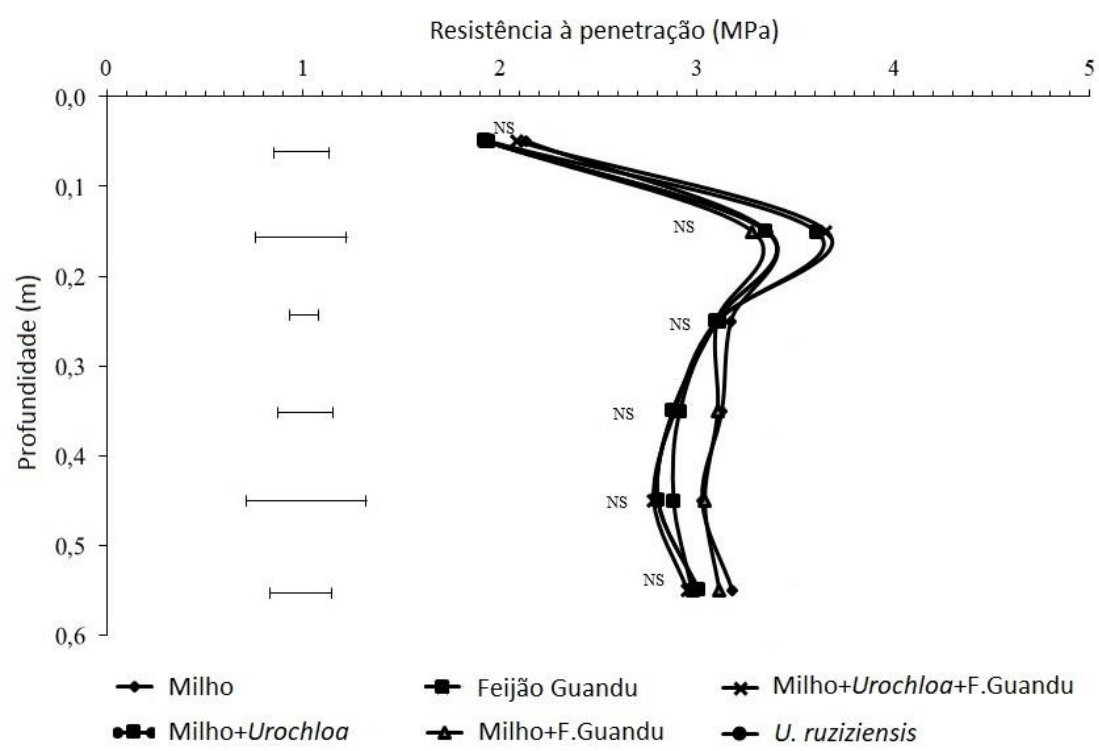

Barras horizontais comparam os valores de resistência à penetração, para cada profundidade, pelo teste DMS (5\%). 
Entretanto, os índices de qualidade estrutural do solo avaliados pelo DRES (Tabela 3), indicam alterações na estrutura do solo com os diferentes tratamentos, corroborando com os resultados encontrados por Valani et al. (2020) que indicam que o DRES é um método com ampla sensibilidade em identificar mudanças de manejo. As menores médias de IQES foram encontrados no Milho solteiro, com notas entre 3,0 e 3,9 que representam o predomínio de agregados com faces planas, poucos poros e atividade biológica e, pode apresentar raízes achatadas com dificuldade para desenvolvimento. Para essas características considera-se um IQES regular de acordo com Ralisch et al. (2017) e, se indica aprimorar o sistema de produção ampliando a diversificação de culturas, incluindo espécies vegetais com alta capacidade de aporte de fitomassa aérea e raízes. Nessas condições de cultivo solteiro toda a parte aérea do milho é colhida, ou seja, não há acumulo de palhada sobre a superfície do solo nem presença de gramíneas após a colheita do milho, gerando um menor escore visual de qualidade em relação ao sistema de integração lavoura pecuária, que detém pastagem na entrelinha dos cereais (GIAROLA et al., 2009).

As maiores médias de IQES foram observadas nos tratamentos com presença de $U$. ruziziensis, com nota 4 ou acima, que representa estrutura friável, pouco grumosa, pouco poros, fraca atividade biológica e, as raízes podem apresentar algum impedimento ao desenvolvimento. Estes aspectos, de acordo com Ralisch et al. (2017) indicam qualidade estrutural boa com evidências de conservação/recuperação, recomendando 0 uso de sistemas de diversificação com alta capacidade de contribuição de fitomassa aérea e radicular.

Tabela 3. Índice de qualidade estrutural do solo (IQES) em um Nitossolo Vermelho cultivado com milho em consórcio com forrageiras no oeste catarinense. Concórdia, SC, 2018.

\begin{tabular}{ll}
\hline Tratamento & IQES \\
\hline Milho & $3,25 \mathrm{c}$ \\
Milho+ F. Guandu & $3,61 \mathrm{~b}$ \\
Milho+U. ruziziensis & $4,02 \mathrm{a}$ \\
Milho+U. ruziziensis + F. Guandu & $4,05 \mathrm{a}$ \\
Feijão Guandu Forrageiro solteiro & $3,70 \mathrm{~b}$ \\
Urochloa ruziziensis solteira & $4,10 \mathrm{a}$ \\
\hline
\end{tabular}

${ }^{1}$ Médias seguidas pela mesma letra na coluna não diferem entre si pelo teste LSD de Fisher $(P<0,05)$.

Os índices mais elevados gerados pela $U$. ruziziensis ocorrem devido a maior atividade biológica e melhores agregados, proporcionados pelo seu sistema radicular agressivo, volumoso e profundo. De acordo com Machado e Assis (2010), a utilização de pastagens em áreas de lavoura, por períodos de dois anos ou mais, pode contribuir para a melhoria da qualidade física dos solos. O sistema radicular da $U$. ruziziensis favorece maior formação e estabilização dos agregados no solo, proporcionado agregados mais resistentes e mantendo a estrutura do solo sem grandes alterações quando submetidos a forças externas, como pisoteio de animais e operações mecanizadas (FERREIRA et al., 2010; BRANDÃO; SILVA, 2012). Os melhores índices de agregação também são explicados pelo incremento de fitomassa depositada na superfície do solo, que após sua decomposição, aumenta a atividade microbiana, o acúmulo de nutrientes e matéria orgânica nas camadas superficiais e, consequentemente, favorece $\mathrm{o}$ aumento da quantidade e estabilidade dos agregados do solo (LOSS et al., 2011).

A presença do F. Guandu apresentou menores índices de alterações no solo em relação a $U$. ruziziensis, pois as espécies de plantas de cobertura da família das gramíneas, que apresentam sistema radicular fasciculado, renovado regularmente, são mais eficientes em aumentar e manter a estabilidade de agregados em relação às leguminosas, além de ser mais facilmente captadas pelo DRES (LOSS et al., 2015). Estudos de Farias et al. (2013) também demonstraram que o F. Guandu tem menor eficiência como planta descompactadora em Latossolo Vermelho, similar ao presente experimento. 


\section{Conclusões}

A presença da Urochloa ruziziensis e/ou do feijão guandu forrageiro não reduz a produtividade de massa seca do milho, mas reduz a PMS da aveia+azevém cultivados em sucessão.

A RSP não se mostrou eficiente em identificar as diferenças entre os tratamentos, entretanto, o DRES identificou que os sistemas com presença Urochloa ruziziensis apresentam os melhores IQES após dois anos dos cultivos consorciados.

O consórcio milho com Urochloa ruziziensis além de não reduzir a produtividade da silagem, propicia disponibilidade de forragem no período de vazio outonal, bem como, melhoria nos atributos do solo o que torna a utilização deste consórcio uma opção de manejo para a região Oeste de Santa Catarina.

\section{Agradecimentos}

Ao Instituto Federal Catarinense pela disponibilidade de recursos financeiros através do Edital № 267/2017 e da estrutura e recursos humanos do campus Concórdia.

\section{Referências}

BORGHI, E.; CRUSCIOL, C. A. C. Produtividade de milho, espaçamento e modalidade de consorciação com Brachiaria brizantha no SPD.

Pesquisa Agropecuária Brasileira, v.42, n.2, p.163-171, 2007. https://doi.org/10.1590/S0100$\underline{204 \times 2007000200004}$

BRANDAO, E. D.; SILVA, I. F. Formação e estabilização de agregados pelo sistema radicular de braquiária em um Nitossolo Vermelho. Ciencia Rural, v.42, n.7, p.1193-1199, 2012. https://doi.org/10.1590/s0103-

84782012000700009

CALONEGO, J. C.; BORGHI E.; CRUSCIOL C. A. C. Intervalo hídrico ótimo e compactação do solo com cultivo consorciado de milho e braquiária. Revista Brasileira de Ciência do Solo, v.35, n.6, p.2183-2190, 2011a. https://doi.org/10.1590/S0100$\underline{06832011000600033}$

CALONEGO, J. C.; GOMES, T. C.; SANTOS, C. H.; TIRITAN, C. S. Desenvolvimento de plantas de cobertura em solo compactado. Bioscience Journal, v.27, n.2, 2011b.
CEPA. Síntese Anual da Agricultura de Santa Catarina. Florianópolis: Epagri/Cepa, 2018. v.1. 206p. Disponível em: http://docweb.epagri.sc.gov.br/website_cepa/pu blicacoes/Sintese_2017_18.pdf. Acesso em: 08 maio 2019.

COLLARES, G. L.; REINERT, D. J.; REICHERT, J. M.; KAISER, D. R. Compactação de um Latossolo induzida pelo tráfego de máquinas e sua relação com o crescimento e produtividade de feijão e trigo. Revista Brasileira Ciência do Solo, v.32, n.3, p.933- 942, 2008. https://doi.org/10.1590/5010006832008000300003

COLLARES, G. L.; REINERT, D. J.; REICHERT, J. M.; KAISER, D. R. Compactação superficial de Latossolos sob integração lavoura: pecuária de leite no noroeste do Rio Grande do Sul. Ciência Rural, v.41, n.2, p.246-250, 2011. https://doi.org/10.1590/S0103-

$\underline{84782011000200011}$

COSTA, J. A. A.; NEVES, A.; SILVEIRA, L.; VILLAFUERTE, S.; GUIMARAES, R.; PROCIÚNCULA, G. C.; QUEIROZ, H. P. Consórcio de guandu com milho ou com sorgo para produção de silagem. Embrapa Caprinos e OvinosComunicado Técnico (INFOTECA-E), 2017a.

COSTA, N. R.; ANDREOTTI M.; BERGAMASCHINE A. F.; LOPES, K. S. M.; LIMA, A. E. S. Custo da produção de silagens em sistemas de integração lavoura-pecuária sob plantio direto. Revista Ceres, v.62, p.009-019, 2015. http://dx.doi.org/10.1590/0034737X201562010002

COSTA, N. R.; ANDREOTTI, M.; CRUSCIOL, C. A. C.; LIMA, C. G. R.; CASTILHOS, A. M.; SOUZA, D. M.; BONINI, C. S. B.; PARIZ, C. M. Yield and nutritive value of the silage of corn intercropped with tropical perennial grasses. Pesquisa Agropecuária Brasileira, v.52, n.1, p.63-73, 2017b. https://doi.org/10.1590/s0100$\underline{204 \times 2017000100008}$

COSTA, N. R.; ANDREOTTI, M.; GAMEIRO, R. D. A.; PARIZ, C. M.; BUZETTI, S.; LOPES, K. S. M. Adubação nitrogenada no consórcio de milho com duas espécies de braquiária em sistema plantio direto. Pesquisa Agropecuária Brasileira, v.47, n.8, p.1038-1047, 2012. 
https://doi.org/10.1590/S0100-

\section{X2012000800003.}

CQFSRS/SC. Manual de Calagem e Adubação para os estados do Rio Grande do Sul e Santa Catarina. 11. ed. 2016. 376 p.

CRUSCIOL, C. A. C.; SORATTO, R. P.; BORGHI, E.; MATEUS, G. P. Benefits of integrating crops and tropical pastures as systems of production. Better Crops, v.94, n.2, p.14-16, 2010

CRUSCIOL, C. A.C.; NASCENTE, A. S.; BORGHI, E.; SORATTO, R. P.; MARTINS, P. O. Improving Soil Fertility and Crop Yield in a Tropical Region with Palisadegrass Cover Crops. Agronomy Journal, v.107, n.6, p.2271-2280, 2015. http://dx.doi.org/10.2134/agronj14.0603

EMBRAPA. Estação Agrometeorológica da Embrapa Suínos e Aves. 2017. Disponível em: http://www.cnpsa.embrapa.br/meteor/. Acesso em: 13 jul. 2017.

FARIAS, L. N.; BONFIM-SILVA, E. M.; PIETROSOUZA, W.; VILARINHO, M. K. C.; SILVA T. J. A.; GUIMARÃES, S. L. Características morfológicas e produtivas de feijão guandu anão cultivado em solo compactado. Revista Brasileira de Engenharia Agrícola e Ambiental, v.17, n.5, p.497-503, 2013. https://doi.org/10.1590/S1415$\underline{43662013000500005}$

FERREIRA, D. F. Sisvar: a computer statistical analysis system. Ciência e Agrotecnologia, v.35, n.6, p.1039-1042, 2011. https://doi.org/10.1590/S141370542011000600001

FERREIRA, R. R. M.; TAVARES, J.; FERREIRA, V. M.; Efeitos de sistemas de manejo de pastagens nas propriedades físicas do solo. Ciências Agrárias, v.31, n.4, p.913-932, 2010.

FLORES, J. P. C.; ANGHINONI, I.; CASSOL, L. C.; CARVALHO, P. C. F.; LEITE, J. G. B.; FRAGA, T. I. Atributos físicos do solo e rendimento de soja em sistema plantio direto em integração lavourapecuária com diferentes pressões de pastejo. Revista Brasileira Ciência do Solo, v. 31, n. 4, p. 771-780, 2007. http://dx.doi.org/10.1590/S0100$\underline{06832007000400017 .}$.
GIAROLA, N.F.B.; TORMENA, C.A.; SILVA, A.P.; $B A L L, B$. Método de avaliação visual da qualidade da estrutura aplicado a Latossolo Vermelho Distroférrico sob diferentes sistemas de uso e manejo. Ciencia Rural, v.39, n.8, p.2531-2534, $2009 . \quad$ https://doi.org/10.1590/S010384782009000800041

HAKANSSON, I.; VOORHEES, W.B.; RILEY, H. Vehicle and wheel factors influencing soil compaction and crop response in different traffic regimes. Soil and Tillage Research, v.11, n.3-4, p.239-282, 1988. https://doi.org/10.1016/01671987(88)90003-7

KUNZ, M.; GONÇALVES, A. D. M. A.; REICHERT, J. M.; GUIMARÃES, R. M. L.; REINERT, D. J.; RODRIGUES, M. F. Compactação do solo na integração soja-pecuária de leite em latossolo argiloso com semeadura direta e escarificação. Revista Brasileira de Ciência do Solo, v.37, n.6, p.1699-1708, 2013.

http://dx.doi.org/10.1590/S0100$\underline{06832013000600026}$

LOSS, A.; BASSO, A.; OLIVEIRA, B. S.; KOUCHER, L. D. P.; OLIVEIRA, R. A. D.; KURTZ, C.; COMIN, J. J. Carbono orgânico total e agregação do solo em sistema de plantio direto agroecológico e convencional de cebola. Revista Brasileira de Ciência do Solo, v.39, n.4, p.1212-1224, 2015. https://doi.org/10.1590/01000683rbcs20140718.

LOSS, A.; PEREIRA, M. G.; ANJOS, L. H. C.; GIACOMO, S. G, PERIN, A. Agregação, carbono e nitrogênio em agregados do solo sob plantio direto com integração lavoura-pecuária. Pesquisa Agropecuária Brasileira, v.46, n.10, p.568-76, $2011 . \quad$ https://doi.org/10.1590/S0100$204 \times 2011001000022$.

LUCIANO, R. V.; ALBUQUERQUE, J. A.; COSTA, A.; BATISTELLA, B.; WARMLING, M. T. Atributos físicos relacionados à compactação de solos sob vegetação nativa em região de altitude no Sul do Brasil. Revista Brasileira de Ciência do Solo, v.36, n.6, p.1733-1744, 2012. https://doi.org/10.1590/\$0100$\underline{06832012000600007}$

MACEDO, M. C. M. Integração lavoura e pecuária: - estado da arte e inovações tecnológicas. Revista Brasileira de Zootecnia, v.38, p.133-146, 
2009.

https://doi.org/10.1590/S1516-

\section{$\underline{35982009001300015}$}

MACHADO, L. A Z.; ASSIS, P. G. A. Produção de palha e forragem por espécies anuais e perenes em sucessão à soja. Pesquisa Agropecuária Brasileira, v.45, n.4, p.415-422, 2010. https://doi.org/10.1590/S0100-

204X2010000400010.

PARIZ, C. M.; ANDREOTTI, M. AZENHA, M. V.; BERGAMASCHINE, A. F.; MELLO, L. M. M.; LIMA, R. C. Massa seca e composição bromatológica de quatro espécies de braquiárias semeadas na linha ou a lanço, em consórcio com milho no sistema plantio direto na palha. Acta Scientiarum. Animal Sciences, v.32, n.2, p.147-154, 2010. https://doi.org/10.4025/actascianimsci.v32i2.849 $\underline{8}$

PARIZ, C. M.; COSTA, C.; CRUSCIOL, C. A. C.; MEIRELLES, P. R. L.; CASTILHOS, A. M.; ANDREOTTI, M.; COSTA, N. R.; MARTELLO, J. M.; SOUZA, D. M.; PROTES, V. M.; LONGHINI, V. Z.; FRANZLUEBBERS, A. J. Production, nutrient cycling and soil compaction to grazing of grass companion cropping with corn and soybean. Nutrient Cycling in Agroecossystems, v.108, n.1, p.35-54, 2017. http://dx.doi.org/10.1007/s10705016-9821-y

PORTES, T. D. A.; CARVALHO, S. I. C. D.; OLIVEIRA, I. P. D.; KLUTHCOUSKI, J. Análise do crescimento de uma cultivar de braquiária em cultivo solteiro e consorciado com cereais. Pesquisa Agropecuária Brasileira, v.35, n.7, p.1349-1358, 2000.

RALISCH, R.; DEBIASI, H.; FRANCHINI, J. C.; TOMAZI, M.; HERNANI, L. C.; MELO, A. S.; SANTI, A.; MARTINS, A. L. S.; BONA, F. D. Diagnóstico Rápido da Estrutura do Solo - DRES. Londrina: Embrapa Soja, 2017.64p

RAYOL, B. P.; ALVINO-RAYOL, F. O. Uso de feijão guandú (Cajanus cajan (L.) Millsp.) para adubação verde e manejo agroecológico de plantas espontâneas em reflorestamento no estado do Pará. Revista Brasileira de Agroecologia, v.7, n. 1, p. 104-110, 2012.
SALVADOR, F. L. Germinação e emergência de plantas daninhas em função da luz e da palha de cana-de-açucar (Saccharum spp). 2007. Dissertação (Mestrado) - Escola Superior de Agricultura Luiz de Queiroz, Piracicaba, 2007.

SANTOS, H. G.; JACOMINE, P. K. T.; ANJOS, L. H. C.; OLIVEIRA, V. A.; LUMBRERAS, J. F.; COELHO, M. R.; ALMEIDA, J. A.; ARAUJO FILHO, J. C.; OLIVEIRA, J. B.; CUNHA, T. J. F. Sistema Brasileiro de Classificação de Solos. 5. ed. Brasília: Embrapa, 2018. 353p.

SCHEFFER-BASSO, S. M.; AGRANIONIK, H.; FONTANELI, R. S. Acúmulo de biomassa e composição bromatológica de milhetos das cultivares comum e africano. Revista Brasileira de Agrociência, v.10, n.4, p. 483-486, 2004.

STOLF, R. Teoria e teste experimental de fórmulas de transformação dos dados de penetrômetro de impacto em resistência do solo. Revista Brasileira de Ciência do Solo, v.15, p.229-235,1991.

TEDESCO, M. J.; GIANELLO, C.; BISSANI, C. A.; BOHNEN, H.; VOLKWEISS, S.J. Análise de solo, plantas e outros materiais. 2. ed. Porto Alegre, Departamento de Solos da Universidade Federal do Rio Grande do Sul. 1995. 174p. (Boletim Técnico de Solos; 5)

TORRES, E.; SARAIVA, O. F. Camadas de impedimento do solo em sistemas agrícolas com a soja. Londrina: Empresa Brasileira de Pesquisa Agropecuária, 1999. 58p. (Circular técnica; 23)

VALANI, G. P.; VEZZANI, F. M.; CAVALIERIPOLIZELI, K. M. V. Soil quality: evaluation of onfarm assessments in relation to analytical index. Soil and Tillage Research, v.198, p. 104565, 2020. https://doi.org/10.1016/j.still.2019.104565

ZHANG, S. J.; CHAUDHRY, A. S.; OSMAN, A.; SHI, C. Q.; EDWARDS, G. R.; DEWHURST, R. J.; CHENG, L. Associative effects of ensiling mixtures of sweet sorghum and alfalfa on nutritive value, fermentation and methane characteristics. Animal Feed Science and Technology, v. 206, p.29-38,

2015. https://doi.org/10.1016/j.anifeedsci.2015.05.006 